\title{
Preliminary Probe into the Teaching Reform of Statistics Specialty in The Age of Big Data
}

\author{
$X U \mathrm{Hui}^{1,}$ a,$X U \mathrm{He}^{2, \mathrm{~b}}$ \\ ${ }^{1}$ College of Mathematics and Statistics, Baicheng Normal University, Baicheng,137000,China \\ ${ }^{2}$ Civil Affairs Bureau of Taobei District, Baicheng,137000, China \\ aemail: 358999206@qq.com, bemail:76016042@qq.com
}

Keywords: The Age of Big Data, Statistics Specialty, Teaching Reform

\begin{abstract}
This paper gives a brief introduction to big data and its significance, expounds the influence brought about by big data, and makes a deep research and analysis on the teaching reform of statistics major in the era of big data. It is hoped that it can provide some reference and help to the teaching reform of statistics major in big data's time, so that the teaching of statistics specialty can better meet the actual needs of current society and promote the progress of social and economic development in our country.
\end{abstract}

\section{Introduction}

Big data involves huge amounts of data, complex structures, and multidisciplinary data. Data from different disciplines merge with each other, and the boundaries before disciplines become more and more blurred. In terms of data types, there are not only text data, but also a lot of images and videos. Data information such as network. Statistics is mainly to study the nature of various phenomena, laws and comprehensive analysis and processing of data. Big data era, Statistics majors are becoming more and more important in social and economic development. Statistics majors themselves have very strict requirements in mathematical theory knowledge and professionalism. Big data's time not only brought great opportunities for the development of statistics majors. Statistics majors are also facing a very severe test. The past teaching methods of statistics majors have been unable to meet the actual teaching needs of statistics majors in big data's time. It is necessary to reform and optimize the traditional teaching methods. In this paper, research and analysis are carried out.

\section{Big Data and Its Significance}

The current big data environment has the following aspects: first, more and more stream data, new data, the current computer computing ability and storage capacity is very difficult to meet the current data flow needs; second, disk storage restrictions, Close to memory has been difficult to meet data storage needs, more data information needs to be stored to hard disk; thirdly, distributed storage, data information may be stored in several different computers; finally, multi-line state, Data on a computer may be shared by multiple different processors.

With the development of big data, more in-depth research has been carried out on the mechanism of data generation, which has transformed the data into the data information that people need, and at the same time has played a certain reference and influence on the formulation of policy and system. This process takes a long time and effort. That is to say, big data has the ability to preserve the social and natural status quo. At present, people are collecting more and more data and information, although the analysis of big data is not very clear. But it is generally believed that the preservation of these data will be of great value in the future. Big data's applications, such as microscopes and telescopes, can be used to analyze nature, society and economy effectively. Under Internet data, timely grasp the information resources needed. Big data, in practical applications, can not only help people to explore the current scientific problems in depth, but also can be applied to the impact of genetically modified foods on future generations, etc. To provide valuable information for future 
human research[1].

\section{The Influence of Big Data}

The emergence of big data has a great impact on the development of the times.Big data era, people will be driven by the data to carry out a more in-depth study of the problem.For example, when traveling, first inquire about the local weather and traffic and so on.In ancient Greece, philosophers were known as encyclopedias. With the development of science, different industries had their own experts. In big data's time, there would be encyclopedic missions again.It weakens the authority of experts in various fields, and even makes the subject experts die out gradually.As statisticians collect more and more data, for example, the rising level of data processing will gradually take the place of life science experts in the life sciences[2].In addition, we can use related translation websites and software to achieve translation purposes, no longer need to seek specialized translators.

\section{Current Situation of Statistics Teaching in The Age of Big Data}

With the rapid development of science and technology, the ways and means of obtaining information data have been changed greatly. The development of electronic commerce and the application of more and more new media technology make the traditional teaching of statistics face great challenges. On the one hand, when people accept data information passively, they will also actively seek and obtain the data information they need. There are some differences in data requirements among different disciplines. On the other hand, with the increasing amount of information data, People are more passive in data collection, and statistics need to explore a new kind of statistical model[3]. For example, in the field of economics, experts are conducting daily survey data and observation data collection, in the field of natural sciences. Experts not only collect astronomical data, but also microcosmic genetic data. Different people have different methods of data collection, some of them collect data through the laboratory. Some people collect data through network and so on. The challenges brought by big data era to statistics majors mainly focus on different formats, structural data processing, data source tracking, abnormal data processing, problem analysis and decision making and so on.

\section{Implementation of Teaching Reform of Statistics Specialty in The Age of Big Data}

At present, experts and scholars at home and abroad have carried out a large number of practical studies on the curriculum reform of statistics major. Combining with the current teaching situation in our country and the reform of statistics major, we should not only raise the requirements for students in the fields of mathematics foundation, but also in the following aspects:. At the same time, we also need to pay attention to the improvement of students' computer application, statistical thought and the ability of analysis and processing.

Curriculum Teaching Method Reform. In the past, the teachers of statistics major mainly combined with the syllabus to explain the relevant knowledge content, and the emphasis of the teaching was on introducing the learning methods to the students. Students learn more statistics theories and methods, and statistics work requires students to have a very good learning ability in statistical software and models, knowledge of computer, mathematics, etc. In this way, students can independently analyze and observe some economic problems in society. Therefore, in the course of classroom teaching, the teacher can combine with the students' characteristics and teaching contents to provide the students with the guidance of targeted teaching methods, and guide the students to learn to analyze and summarize through scientific teaching methods. Induction. In the application of statistical model case teaching, preclass reading and classroom discussion are the main links, through the case teaching method, can help students to grasp the relevant knowledge more quickly. Teachers guide the students in order to master the relevant knowledge in the process of problem exploration and thinking, realize the solution and inspiration of the questions, and improve the 
students' creative thinking and independent thinking. A successful discussion class should first create a free and comfortable atmosphere for students to participate in class discussions easily and happily. In addition, the teacher can organize the classroom discussion to have a detailed understanding of the actual situation of the students, in the later teaching process more targeted[4].

The teaching of statistics specialty should be based on the characteristics of the subject and pay more attention to the application of statistics. Do a good job of training and training the students' practical application ability. During the teaching process, teachers can introduce some current hot issues. Through problem analysis, students can feel the future development and direction of statistics more intuitively. If the teacher only teaches students statistical methods in the teaching process, they do not pay attention to the explanation of actual cases and background, etc. Then the students will be more unfamiliar in the practical application of the model, in the later statistical work is more rigid, so that students' creative thinking ability and innovation ability is limited.

The model of teaching statistics can be combined with the reality, expounds the application background of the statistical theory and statistical conditions, the basic idea, to reduce the proportion of pure theoretical knowledge in the classroom teaching. On the one hand, pay attention to the application and training of the students' statistical software, on the other hand, the statistical methods in the course of teachers also need to be equipped with computer the experimental teaching content, the teaching effectiveness can be improved[5].

Construction of Practical Teaching Links. The development of statistics is closely related to practice. The significance of statistics is to meet the needs of society. Only in practice can statistics be better perfected and strengthened. It is difficult for students to give full play to their statistical knowledge and skills in short time after graduation. In big data's time, the society needed statistics talents with strong comprehensive accomplishment, practical ability and solid professional foundation. Therefore, in the teaching of statistics major, increasing the proportion of practical teaching links, teaching students how to use statistical software, using statistical software to solve some practical problems. To cultivate students' ability to write academic papers and research reports, to make students feel the value of statistics in practical application, and to enhance their initiative in the study of statistics major. Graduation papers and other practical teaching contents are among the easiest to implement. When students are sophomores, they can arrange for students to develop curriculum design, and through curriculum design, they can exercise students' ability in information retrieval, thesis writing, and so on, in the third year of college. Students have basically mastered the basic skills of statistical methods. Teachers can properly train students in writing, such as data analysis reports, so that students can master the standard and standard writing methods of statistical articles. Teach students the practical application of statistical methods, in the senior stage, let students start preparing graduation thesis[6].

In order to cultivate students' enthusiasm for learning, practical ability and innovative ability, practical teaching forms can be enriched in the process of practical teaching. To improve the students' initiative in the study of statistics major, the school can get in touch with the enterprise, establish the practice teaching base outside the school, lead the students to study in the enterprise, let the students do some data analysis as far as they can, and establish the simulation laboratory. To provide students with real data analysis opportunities, do a good job with the community, students after graduation can quickly integrate into the actual work. During the holidays, can call on students to carry out social surveys, so that students' interest in learning has significantly increased. Enhance students' professional literacy. Teachers can design questionnaires to carry out field surveys, guide students to use statistical analysis software to analyze the collected data, and complete the writing of data analysis reports. To publish their own research results, so that the enthusiasm of students have a significant improvement. For students to participate in statistical competition opportunities, students are close to graduation, help students practice units, Organize students to study in enterprises or government units on holidays, prepare practice report after practice[7].

Improving the Effectiveness of the Construction of Teachers. The cultivation of students' practical and innovative abilities can not be separated from the support of a team of professional teachers. As far as statistics teachers are concerned, they can go deep into institutions with high 
statistical level to conduct study visits, or participate in international academic exchange conferences, etc. Teachers should have more profound knowledge, grasp the direction of professional development and understand the latest scientific research trends. Teachers should also actively participate in data analysis and exchange meetings between enterprises to understand the specific needs of statistical professionals in the current market. Adjust the teaching content and curriculum content in time[8].

Young teachers can hang up in units such as the Bureau of Statistics, exercise their practical ability, effectively improve their level of combining practice with theory, and help young teachers grow better. At the same time, it can also better understand the characteristics of industry-school cooperation, strengthen the relationship between schools and society, and provide more employment channels for students while broadening their practical ability. Teachers study through practical projects. Be able to establish a link between practical problems and professional knowledge, analyze the frontier and hot issues in this field, and understand new knowledge skills. The teaching of statistics needs to keep pace with the development of the industry. Better meet the needs of professionals in the process of industry development, only in this way, the students can better meet the actual needs of society.

\section{Conclusion}

In the era of big data, there were not only great opportunities for the development of statistics majors, but also severe tests. If statistics majors want to develop better, they must first make clear their own talent training goals and highlight their characteristics in running schools. To give full play to the value and function of the existing teaching resources. The specialty of statistics has a very strong application. In practical teaching, it is important to improve students' ability to innovate and analyze and solve problems. Better to meet the actual needs of the future society. The combination of professional teaching and practical work to better serve the society and promote the benign development of statistics in China.

\section{References}

[1]ZHOU Li,GUO Xiangxin. Exploration on Teaching Reform of Statistics Major in Agricultural Colleges and Universities[J]. Education Teaching Forum,2017,(44):138-139.

[2]GUO Dong. Research on the Cultivation and Teaching Reform of Statistics Specialty from the Perspective of Employment[J].Statistics \& Information Forum,2017,(11):127-128.

[3]HE Lin. Research on the Optimization of practice Teaching system in Statistics Specialty[J]. Journal of Hubei Correspondence University,2017,(10):129-130.

[4]ZHU Changhua,WU Yingxun. Analysis of the present Employment situation of Statistics Major in Shaoguan University[J]. Journal of Shaoguan University,2017,(8):35-38.

[5]JIANG Chunxi. Research on the Teaching method of Software course for Statistical Professionals[J]. Journal of Heihe University,2017,(10):128-129,187.

[6]ZHANG Xuexin. Exploration on the Practice of Statistics Major in Big Data Company[J]. University Education,2017,(12):47-49,94.

[7]ZHAO Shengli. Constructing the Curriculum System of Statistics Specialty to Meet the Needs of the Society[J].Journal of Qufu Normal University(Natural Science),2017,(3):121-124.

[8]SONG Liying, ZHAO Linlong.Thoughts on the Development of Statistics Specialty[J].Statistics \& Information Forum,2015,(2):106-112. 